\begin{tabular}{lllllllllllllllllllllllllllllllll}
\hline$R$ & $E$ & $V$ & I & S & T & A & D & E & E & S & T & U & D & I & O & S & I & N & T & E & R & N & A & C & I & O & N & A & L & E & S
\end{tabular}

\title{
Las Naciones (des) Unidas después de la guerra de Irak ${ }^{*}$
}

Walter Sánchez

El principal rasgo político de la guerra de Irak fue el alto nivel de desunión y la falta de concertación política que predominó entre los países involucrados. Este clima, enrarecido por las sospechas y recriminaciones mutuas, puede convertirse en una bola de nieve, a menos que predomine una diplomacia preventiva que apunte a articular los gobiernos, la opinión pública, los Estados y las organizaciones formales e informales. El título del artículo señala esta problemática y a partir de esa realidad sugiere algunas alternativas para mejorar el sistema de modo de aumentar los niveles de cooperación en el plano de la seguridad internacional.

\section{INTRODUCCIÓN}

1 1 shock de la guerra de Irak llevó a figuras célebres como Kenneth Waltz, uno de los fundadores del neorrealismo, Thomas Schelling y otros 32 internacionalistas destacados a enviar una carta al New York Times, oponiéndose a la guerra en Irak. Por su parte, Henry Kissinger discrepó de los métodos, aunque aprobó la guerra por razones geopolíticas. La izquierda encontró una bandera para su agenda antiimperialista. Aun- que es contrario al neorrealismo, Chomsky sostiene que lo que mueve al imperio es la conquista de recursos, especialmente el petróleo, y que la lucha contra el terrorismo y en favor de la democracia son un disfraz para satisfacer intereses geoeconómicos.

La industria mediática, al servicio de la ideología de la entretención, optó por recrear comunicacionalmente el clima de reality, destacando el protagonismo del mensaje. Sin embargo, en vez de analizarlo en profundidad subió a sus corres-

* Con el apoyo del Proyecto de Enlace DI 2003 del Departamento de Investigación, Vicerrectoría de Investigación y Desarrollo de la Universidad de Chile. 
ponsales arriba de los tanques. Más allá del golpe mediático de la denominada Spectacle war, se pretende prospectar tendencias estructurales en medio de la bruma de la guerra, nebulosa que desapareció tras la victoria militar, para ser reemplazada por una densa neblina política de posguerra.

La hipótesis de este artículo, sin negar la existencia de causales valóricas, jurídicas, económicas y geopolíticas, apuesta por el predominio de causales políticas. Para comprobarla se optó por un enfoque del realismo estructural, es decir, ocupar algunas categorías del realismo unidas a otras de carácter sistémico, en particular, los aportes de las teorías relativas a los regímenes internacionales ${ }^{1}$.

\section{La industria mediática subió a sus corresponsales a los tanques.}

Toda sugerencia que pueda derivarse para reformar el sistema de cooperación en el área de la seguridad tiene como punto de partida una adecuada apreciación de la correlación de fuerzas en la coyuntura post Irak.

\section{I . LOS ERRORES DE LA POLÍTICA Y LA DIPLOMACIA}

Mientras que la caída del Muro de Berlín se celebró en las calles como vic- toria de la política en beneficio del género humano, con la reciente guerra de Irak ocurrió lo contrario. Como señaló la presidenta del Carnegie Endowment en un número especial de Foreign Policy sobre el mundo post Irak: "El período de post guerra será una prueba decisiva para saber si esta tendencia negativa puede revertirse, si a diferencia de lo ocurrido en Afganistán durante los años ochenta, la intervención en Irak será una victoria militar seguida de una costosa derrota política"'.

$\mathrm{El}$ artículo sostiene que la guerra de Irak fue provocada en parte por fallas políticas estructurales, es decir, por el aflojamiento de los sistemas de alianzas, que aumentaron los niveles de indisciplina y desunión entre los países. En particular, se escindió el eje que sostiene la balanza de poder mundial debido a las diferentes visiones sobre éste y sus usos después del 11/09.

En la medida en que aumentó la sensación de temor, crecieron los síntomas de una eventual anomia internacional y frente a esta amenaza de disolución del statu quo, los actores centrales aprovecharon la coyuntura para enviar una fuerte señal unilateral de disciplinamiento del sistema. Para reacomodar el orden de post guerra, estarían dispuestos a pagar los costos y aceptar algunos principios generales y marcos regulatorios multilaterales.

Si bien la situación no se rigió por los principios generales de las Naciones Uni-

${ }^{1}$ Nye S., Joseph Jr. La paradoja del Poder Norteamericano, Santiago de Chile, Taurus, 2003. Ver Cap. 5. "La Batalla entre los universalistas y los multilateralistas"; pp. 212-224.

${ }^{2}$ Tuchman, Jessica. "Now for the hard part", Foreign Policy, № 137, July-August, 2003. 
das habría interés en intentar un $u p$ grading de los regímenes de cooperación en el área de la seguridad. Asegurar los beneficios que significa operar en un entorno político post bélico, más predecible $\mathrm{y}$ sin los siderales gastos de un excesivo unilateralismo, no es filantropía sino realismo.

La sensación de recelo e inseguridad que produjo la guerra de Irak fue un tema clave de la agenda comunicacional. Por lo tanto, ante la amenaza de nuevas guerras asimétricas y terroristas, también sostenemos que existe un clima favorable para reorganizar la "gobernanza global", en particular el Consejo de Seguridad de las Naciones Unidas. Si no se trata de innovar ahora, se desaprovecharía la mejor coyuntura para hacerlo.

El supuesto en que descansan estas hipótesis políticas es que a largo plazo, la trampa de un unilateralismo ciego puede llevar a una guerra de guerrillas de todos contra todos. Por unilateralismo se entiende "to opt out of a multilateral framework (whether existing or proposed) or to act alone in adressing a particular global or regional challenge rather than choosing to participate in collective action...because they do not wish to subject themselves to the generalized principles being negotiated or enforced, or they may find such principles inimical to their national interests..."3. Llevada al extremo, esta tendencia política no ofrecería garantías de durabilidad, eficacia y legitimidad. Sería el peor riesgo para la paz y la democracia y el más propicio aliciente para una guerra sin fin, que a su vez gatillaría una estampida armamentista acompañada de ciclos menos democráticos.

\section{Hay un clima favorable para reorganizar la gobernanza global.}

No obstante reconocerse los errores políticos y diplomáticos cometidos por todos los actores, esta vez el sistema no funcionó y hubo fallas estructurales que deben repararse antes de que vuelva a caer. Aunque las responsabilidades son desiguales, todos los actores fracasaron políticamente. Como lo señaló Juan Pablo II, la guerra fue un retroceso para la Humanidad $^{4}$.

Hacia el futuro, una diplomacia preventiva debería garantizar el bien colectivo de la paz mediante un sistema eficiente para el manejo multilateral de los conflictos $^{5}$. En la guerra virtual o guerra espectáculo, los televidentes, agresores o agredidos, son atraídos por armas veloces, inteligentes, high tech, a control remoto y a larga distancia, muy lejos del

\footnotetext{
${ }^{3}$ Malone, David and Yuen Foong, Khong. Unilateralism and U.S. Foreign Policy. International Perspectives. 2003, London, Lynne Rienner, 2003; p. 5.

${ }^{4}$ Zenit.org.com, Ciudad del Vaticano, 20 de febrero, 2003, "La guerra derrota para la humanidad y tragedia para la religión": "No se debe permitir que la amenaza de guerra ni la guerra propiamente tal aleje a cristianos, musulmanes, budistas, hindúes y miembros de otras religiones".

${ }^{5}$ Hampson, O. Fen and David Malone. From Reaction to conflict prevention. Opportunities for the UN system, London, Lynne Rienner, 2002.
} 
suelo patrio. Esas batallas virtuales provocaron un estado de agitación permanente de la población, que fue intoxicada y desinformada con verdades a medias. Como consecuencia de ello, ya ingresamos a la etapa de poner en duda la credibilidad de los argumentos y la verosimilitud en la conducción de la guerra ${ }^{6}$.

Pese a sus defectos, el Consejo de Seguridad de Naciones Unidas tiene credibilidad pero perdió una oportunidad viable de prevenir la guerra e imponer la paz mediante un "multilateralismo", al menos formal. El sistema no funcionó y cada actor actuó solo y demostró ser capaz de salirse con la suya. La sensación de impunidad internacional creció entre los Estados y los ciudadanos, por lo que concluimos que la actual coyuntura post bélica es más favorable para crear instituciones multilaterales de tercera generación y renovadas. Existe una oportunidad histórica para avanzar en la institucionalización de una diplomacia multilateral y preventiva, por lo tanto es bienvenido un up grading de los principios generales, origen, composición y gestión de las Naciones Unidas y su Consejo de Seguri$\mathrm{dad}^{7}$.

El Consejo no suple las carencias de poder de cada uno sus miembros y, por sí, no es ni será un segundo polo para mantener a Estados Unidos dentro del sistema internacional. Individualmente, sus miembros no pueden imponer un sistema multipolar. A veces con fines propagandísticos, muchos líderes de opinión estadounidenses estarían usando el mismo procedimiento del unilateralismo ciego para contener esa tendencia. Con cierta razón, Robert Kagan ha criticado el multilateralismo europeo "a partir del hecho de que refleja la debilidad de Europa". En su argumento, "la visión multilateralista sólo es posible porque los europeos pueden descansar en la fuerza del poderío militar de los Estados Unidos"8.

\section{La estructura mundial del poder es unipolar en lo militar.}

La presente lectura, realista y sistémica, reconoce que la estructura mundial del poder es unipolar en lo militar, con evidente predominio de una paz americana multipolar en lo económico. Pero también hay otro tipo de poder, que Joseph Nye denomina softpower, y define como "el reino de las relaciones transnacionales que cruzan las fronteras más allá del control de los gobiernos...Este softpower es muy disperso y no tiene sentido hablar de unipolaridad, multipolaridad o hegemonía"9. En esta materia, la situación se presta para crear regímenes políticos que hagan posible la cooperación entre los miembros de la sociedad

${ }^{6}$ Kagan, Robert, "Looking for legitimacy in all the wrong places", Foreign Policy, № 137, julioagosto 2003.

${ }^{7}$ Glennon, Michael. "Why the Security Council failed", Foreign Affairs, V. 82, № 3, May-June, 2003.

${ }^{8}$ Kagan, Robert. op. cit.; p. 15.

${ }^{9}$ Nye S., Joseph Jr. "La paradoja del poder norteamericano", op. cit.: "Lograr que otros ambicionen lo que uno ambiciona es lo que yo llamo poder blando"; p. 30. 
civil para lograr bienes colectivos para la humanidad. Para llevar adelante esta tarea habrá que aumentar la representación de la sociedad civil en los organismos de seguridad y cooperación mundiales. Ésta es una tendencia irreversible, indirecta y a largo plazo. Para que sea duradera, toda innovación de los sistemas de seguridad en Estados Unidos, en Europa y en el Consejo de Seguridad tendría que reconocer estas realidades y volver a colocar las cosas en su lugar.

II. ¿EL FIN DEL “ATLANTISMo” DESPUÉS DE LA GUERRA DE IRAK?

En la guerra de Irak, Estados Unidos, con el apoyo de Inglaterra y España, se alinearon en favor de una estrategia unilateralista como procedimiento válido para la "gobernanza global".

El eje franco-alemán, con el apoyo de Rusia, perdió porque el Consejo de Seguridad fue sobrepasado y no se reunió para legitimar el uso de la fuerza. En cambio, los autodenominados "multilateralistas" lograron un cuasi empate político, ante el doble fracaso de la diplomacia de los Estados Unidos y del Consejo de Seguridad.

La "vieja Europa” capitalizó la masiva simpatía antibélica de la opinión pública mundial y este aparente acierto político condujo al espejismo de creer que nacía un segundo polo de poder capaz de contener a Estados Unidos; sobre todo, sin tomar en cuenta a China, Rusia y la India. Este texto no escrito del discurso franco-alemán llevó a confundir el concepto multilateral con la multipolaridad, lo que explicaría su enorme interés por engrandecer el papel del Consejo de Seguridad.

\section{La vieja Europa capitalizó la simpatía antibélica de la opinión pública mundial.}

Las desavenencias valóricas y conceptuales entre Estados Unidos y Europa se reflejaron en los editoriales de prensa que revelaron la molestia de sus lectores. Como actores políticos, los periódicos y los medios cumplieron un papel clave en la guerra de Irak. De ellos se deduce que la prensa influyente de Estados Unidos acusó a Francia y Rusia de ser los abogados de Saddam Hussein ante el Consejo de Seguridad ${ }^{10}$. El discurso con ribetes mesiánicos y teológicos de Bush Jr. tuvo mala prensa, porque Europa es una sociedad más secular. Lo mismo ocurrió con las figuras de Schroeder y Chirac en los medios escritos estadounidenses.

En su dimensión estructural, un legado negativo de la guerra de Irak es que aumentó la tensión entre la OTAN y la Unión Europea ${ }^{11}$. La seguridad europea post Irak tratará de buscar sistemas de autodefensa regional, alejarse de Estados

${ }^{10}$ Lambert, Richard. "Misunderstanding Each Other", Foreign Affairs, V. 82, № 2, march-april 2003.

${ }^{11}$ The Economist, april, 12-18, 2003. "Special report War in Irak", The Economist, May 24, 2003. "Charlemagne, France's on horse back". 
Unidos y del viejo esquema de la OTAN. Por su parte, Europa y Rusia buscan un nuevo relacionamiento, que sin duda cambiará la correlación de fuerzas frente a los Estados Unidos ${ }^{12}$.

Ahora, la democracia ha redimido de sus culpas del pasado imperial a alemanes y franceses. Se han recuperado en lo económico y luchan por su unidad y autonomía política. La herencia espiritual de su ethos cultural es puesta en jaque. Trajo consigo rostros y países cuyas identidades son desconocidas, los ex países comunistas y otros dispuestos a defender sus raíces étnicas y creencias religiosas, pero ávidos de ingresar a cualquier precio al club del eurocapitalismo.

Mientras que en la nueva Constitución Europea el viejo continente se divorcia del cristianismo, en Estados Unidos las presiones de los mismos grupos religiosos conservadores influyen cada vez más en la conducción de la política exterior. Estas tensiones culturales fueron previstas por Samuel Humtington en su obra Clash of civilizations.

Desde una perspectiva estructural, otras causas han ido debilitando la alianza del Atlántico. Para algunos autores realistas ellas son:

1. El fin de la Guerra Fría y la ausencia de un enemigo común debilitó la alianza.

2. El paso de un mundo bipolar a otro multipolar provocará nuevas sorpresas.
3. Los asuntos internos primarán sobre los temas internacionales.

4. Otras visiones ven que en vez de avanzar hacia la multipolaridad, Europa camina hacia el unipolarismo, encabezado por el eje de poder franco-alemán.

5. La alianza con Estados Unidos no es un fin en sí, sino que se justifica en la medida que facilita la integración; es un medio para ganar tiempo y avanzar hacia una mayor identidad europea, hasta lograr crear una pasión comunitaria y una autonomía europea ${ }^{13}$.

\section{La Constitución europea carece de viabilidad en el tiempo sin el soporte de la sociedad civil.}

Ante esta nueva realidad, los franceses se preguntaron cómo frenar el poderío de Estados Unidos. ¿Será una "hiperpotencia", como lo expresó el ex canciller francés Venedrin, o estamos en presencia de "la potencia indispensable", según su colega Madeleine Albright?

En este contexto, el incansable Valéry Giscard d'Estaing, el presidente de la Convención para la Constitución Europea, trata por todos los medios de acercar la UE al ciudadano. Traspasar la integración de los mercados a los ciudadanos y a los corazones, de modo de ir creando la idea de una sola patria comunitaria. Sin ese soporte de la sociedad civil, la Constitución carece de viabilidad en el tiempo.

\footnotetext{
${ }^{12}$ Stent, Angela y Shevtsova, Lilia. “America, Russia and Europe: a Realignment?”, Survival, Vol. 44, No 4, Winter 2002-03.

${ }^{13}$ Kupchan, Charles (ed.). Atlantic Security, Contending Visions, Nueva York, Council of Foreign Relations, 1998.
} 
Todos estos antecedentes ayudarán a explicar por qué antes, durante y después de la guerra de Irak los aliados se miraron al espejo, se desconcertaron y no se reconocieron entre sí. Ahora y por primera vez, después de la guerra se dieron cuenta de que la situación es peligrosa, que nadie sobra y que la unidad de los tres poderes, los Estados Unidos, la UE y las Naciones Unidas, es indispensable para la estabilidad del sistema internacional. A partir de esta nueva relación de fuerzas se debería estructurar un debate para articular las negociaciones entre estos actores. Es un comienzo de consenso irrefutable, porque estos actores fueron uno de los protagonistas del fracaso del sistema y por lo tanto, tienen poder para adecuarlo a los nuevos desafíos.

\section{ESTADOS UNIDOS Y SU NUEVO PARADIGMA PARA LA SEGURIDAD INTERNACIONAL}

Según el Instituto de Estudios Estratégicos de Londres, la administración de Bush Jr. continuó el trabajo de revisión estratégica iniciado durante el gobierno de Clinton. Gradualmente, el nuevo equipo de gobierno se inclinó por una reinvención estratégica que dudó de la tradicional política de "contención", porque ésta ya no tenía suficiente credibilidad y se optó por la doctrina estratégica de pre-emption. Al abandonarse la doctrina de la contención, perdió importan- cia el principio de la seguridad colectiva, que es clave en el Consejo de Seguridad. Para los planificadores de la seguridad de Estados Unidos, habría que liquidar o eliminar a un adversario que amenace con capacidades peligrosas antes de que pueda producirse una crisis ${ }^{14}$.

\section{El principio de la seguridad colectiva perdió importancia al abandonarse la doctrina de la contención.}

La tradicional actitud de desconfianza de Estados Unidos hacia autoridades no provenientes de su propia Constitución recrudeció con más fuerza después de la guerra de Irak. Al mismo tiempo, la desconfianza hacia los Estados Unidos aumentó con igual fuerza en el resto del mundo, en especial si se considera que no se han encontrado indicios de AMD y supuestos dispositivos nucleares. Ahora, "los norteamericanos", según el analista neoconservador Robert Kagan, "no siempre podrán decir al mundo, confíen en nosotros, porque nosotros sabemos lo que estamos haciendo"15. La guerra aumentó el poder de Estados Unidos, pero puso en duda su credibilidad.

En su reciente libro, Unilateralism and U.S Foreign Policy, analistas liberales como D. Malone y Y. Khon describieron el fenómeno de la siguiente manera: "Proveniente inextricablemente de la estructura política interna, el concepto y la gran capacidad de convocatoria en favor

\footnotetext{
${ }^{14}$ Dodge, Tody and Steve Simon. "Irak at the crossroads", Adelphi Papers, N ${ }^{\mathrm{o}}$ 354, 2003; p.14.

${ }^{15}$ Kagan, Robert. op. cit.; p. 70.
} 
del fuerte sentimiento de excepcionalismo norteamericano, la convicción de que sus valores e instituciones son los mejores imaginables y de que el mundo necesita adaptarse a los Estados Unidos y no a la inversa. Más profundamente, el excepcionalismo norteamericano puede verse como la convicción de sus ciudadanos de que tiene un destino especial entre las naciones" 16 .

El nuevo paradigma de seguridad significó ingresar a una nueva era post contención, anunciada en el crucial discurso del presidente Bush en West Point, el 1 de junio del 2002, hito histórico que cambió el contenido de la política de contención típica de la Guerra Fría. Según su definición "deterrence means nothing against shadow terrorist networks with no nations or citizens to defend. Containment is not possible when unbalanced dictators with weapons of mass destruction can deliver those weapons on missiles or secretly provide them to terrorists allies" ${ }^{17}$.

El secretario de Estado, Colin Powell, complementó la nueva doctrina de seguridad al sostener ante el Comité de Relaciones Exteriores del Congreso, que: "We have not abandoned containment, we have not abandoned deterrence... We haven't abandoned these time-honoured methods of using our national power... But because of the new terrorist threat that does not respond to theories of containment, a doctrine of pre-emption, or an element of pre-emption in our strategy is appropiate... So see it as an elevation of one of the many tools that we have always had, but don't see it as a new doctrine that excludes or eliminates all the other tools of national security"18.

La tesis que postuló "castigar antes de que me ataquen" ha significado mantener a los rogue states en permanente asedio. Según Walter Slocomb, el derecho a la autodefensa no limitaría la acción de una pre-emption force y sería contraria a los principios básicos del derecho internacional ${ }^{19}$. Según esta visión de la guerra preventiva, si el cálculo de la amenaza es errado se producirían desastres peores o, si actores como la India imitan la idea, podría intervenir contra Pakistán, con las desastrosas consecuencias consiguientes.

\section{Después de Irak, la fuerza militar de Estados Unidos es incontrarrestable.}

$\mathrm{Al}$ respecto, la publicación Estrategia Nacional de Seguridad de la Casa Blanca, de septiembre de 2002, explicó el cambio de esta forma de pensar lo estratégico y la seguridad en los Estados Unidos. Asimismo, se difundió ampliamente la Agenda de Política Exterior de los Estados Unidos y su Estrategia de Seguridad para una Nueva Era, y Ronald Rumsfeld, Condoleezza Rice, Richard

\footnotetext{
${ }^{16}$ Malone, David and Yuen Foong Khong, "Unilateralism and U.S.”, Foreign Policy, op. cit.; 14.

${ }^{17}$ Litwak, Robert S. "The New calculus of Pre-emption", Survival, Vol. 44, No 4, Winter 2002-2003;

${ }^{18}$ Litwak, Robert S. idem; p. 59.

${ }^{19}$ Slocombe, Walter. "Force, pre-emtiom and legitimacy", Survival, V. 45, № 1,Spring 2003; 125.
} p. 58. 
Armitage y el Gral. Richard Myers, se encargaron de ponerla en práctica ${ }^{20}$.

\section{La sensación colectiva de temor aumentó el rechazo de la autoridad supranacional y multilateral.}

Ante los ataques terroristas inéditos del 11-09 y casi en forma simultánea se desinflaron algunos íconos gigantes de las punto.com y se pusieron en duda las promesas excesivas de una defensa digital y del famoso escudo nuclear, que blindaría a los Estados Unidos de todo ataque. Para Donald Rumsfeld, secretario de Defensa, la transformación de la defensa iría mas allá de las armas high tech, que si bien es un elemento esencial del cambio, ahora se trataría de una nueva mentalidad, de nuevas formas de pensar y de luchar. En Estados Unidos el debate tuvo y tiene gran complejidad y proyecciones electorales por cuanto, después de Irak, su fuerza militar es incontrarrestable ${ }^{21}$.

Muchas potencias han demostrado su malestar con la doctrina Bush. Por ejemplo, Igor Ivanov, Canciller de Rusia, criticó a Estados Unidos por imponer por la fuerza en el mundo árabe sus valores democráticos. Washington respondió que ellos ya advirtieron a las dinastías del mundo lo que significa combatir a $\mathrm{Al}$ Qaeda, y que se necesita más y no menos democracia ${ }^{22}$.
En el primer momento, los ataques terroristas despertaron una ola mundial de solidaridad sin precedentes con el pueblo norteamericano. Sin embargo, a mediano plazo el 11-09 tuvo consecuencias disímiles para los miembros de la alianza transatlántica. Para los norteamericanos, el efecto fue comparable al del ataque a Pearl Harbour y la sensación colectiva de temor aumentó los niveles de rechazo hacia toda forma de autoridad supranacional y multilateral dentro y fuera de las fronteras, que coloreó los mapas cognitivos de los que diseñaron la estrategia de la guerra de Irak y el debate del Consejo de Seguridad. Toda dilación equivalía a traición y fue fácil desprestigiar las posiciones negociadoras de Francia y Alemania y el papel de las Naciones Unidas.

En la guerra de Irak, el Viejo Mundo pareció olvidar los favores que le había hecho el Nuevo Mundo en la lucha contra el nazismo y el facismo. Se repitió lo que había ocurrido con los Estados Unidos cuando el país se transformó de pigmeo en gigante, y tampoco reconoció los favores recibidos del Viejo Mundo.

Cuando faltó el enemigo común, se diluyó el elemento unificador de la alianza de la Guerra Fría, y cada actor actuó por su cuenta, de acuerdo con sus intereses y aumentaron los conflictos dentro del bloque. A raíz de los fracasos diplomáticos, la más exitosa alianza de la historia se

\footnotetext{
${ }^{20}$ Departamento de Estado, Periódico Electrónico, Vol.7, Nº 4, 2002.

${ }^{21}$ Schneider, William. "Security Redefined", The Atlantic online, may 27, 2003. Rauch, Jonathan. "After Iraq, the Left Has a New Agenda: Contain America First", The Atlantic online, may 27, 2003.

${ }^{22}$ The Economist, "Taking on the world", March 8, 2003; p. 3-14.
} 
desunió y la bruma de la post guerra siguió detenida igual que durante la guerra.

Mientras duró la Guerra Fría, Estados Unidos tuvo actitudes en favor de regímenes multilaterales, como en la creación de las Naciones Unidas, de la OTAN y de la red de acuerdos comerciales y pactos militares con todos los continentes. Sin embargo, en el período anterior a la caída del Muro de Berlín surgieron visiones contrapuestas. Después de 1989, "para los decisores de Washington la protección de la soberanía nacional generalmente ha significado que sus normas, estándares y leyes deben predominar sobre los internacionales" 23 .

Esta actitud ambigua, falta de coherencia y selectiva contrastó con la adoptada por los europeos, que crearon organismos supranacionales, desde el Tratado de Roma hasta el de Niza, y la ampliación de la Unión Europea a los 25 miembros. Las dos culturas políticas definen el poder nacional desde una óptica muy distinta y las discrepancias se agudizaron después del 11.0924.

\section{IV. ¿JAQUE AL MULTILATERALISMO Y AL EQUILIBRIO EUROPEO?}

Después de la guerra de Irak, la Asamblea General y el Consejo de Seguridad de las Naciones Unidas quedaron en una situación muy débil. En este clima políti- co, nublado por el miedo, las percepciones del multilateralismo de la organización y también de la autoridad de la Unión Europea son más negativas que antes. Por ejemplo, para el Washington Post las Naciones Unidas "son una colección barroca de instituciones, regulaciones y formalismo", mientras que el $N$. Y. Times tiene cinco corresponsales en Europa pero ninguno en Bruselas. Según un informe del North-South Center, antes de la guerra de Irak, las Naciones Unidas ya proyectaban la imagen "de una estructura con crecimiento descontrolado, burocratizada, costosa, mal administrada, corrupta y con personal de poco nivel ${ }^{25}$. Después del espectáculo de desunión en la guerra de Irak, esa visión negativa se hizo más popular que antes.

\section{La estrategia de guerra preventiva venía madurando desde las intervenciones militares en los Balcanes.}

Pero más allá de desaveniencias internas respecto de la naturaleza de la amenaza que constituía el régimen de Irak, la pregunta clave es ¿por qué se dividieron los antiguos aliados? Fundamentalmente, porque Estados Unidos optó por una "estrategia de guerra preventiva" que venía madurando desde de sus intervenciones militares en los Balcanes, donde primero

${ }^{23}$ Malone, David and Yuen Foong Khong. "Unilateralism and U.S.”, Foreign Policy, op. cit.; p.19.

${ }^{24}$ Serfaty, Simon. "Europe enlarged, America Detached", Current History, V. 102, № 662, marzo de 2003.

${ }^{25}$ South Centre, La Reforma de las Naciones Unidas. Una visión desde el Sur para fortalecer y democratizar a la comunidad internacional, Montevideo, Instituto del Tercer Mundo, 1998; p.25. 
actuó unilateralmente y luego legitimó multilateralmente para el bombardeo por las Naciones Unidas.

No se respetó el principio básico de la democracia y de la soberanía que, como dice el Preámbulo de la Carta obliga a las partes firmantes a "reafirmar la fe en la igualdad de derechos de hombres y mujeres y de las naciones grandes y pequeñas". Tampoco funcionó el principio del respeto a la tolerancia e igualdad, según el artículo primero "fomentar entre las naciones relaciones de amistad basadas en el respeto del principio de la igualdad de derechos y al de la libre determinación de los pueblos..." (art.1.2.)

Frente a estos atropellos, cada uno de los actores ofreció sus propias explicaciones. Muchos europeos creen que Estados Unidos intervino en Irak porque sigue siendo prisionero del lobby israelí y para contrapesar esa influencia, la Unión Europea debería apoyar a los palestinos contra Israel. Washington interpretó esa actitud antijudía de los europeos como si en el viejo continente no hubiese muerto el antisemitismo.

Para muchos europeos, la intervención de Estados Unidos contra el régimen de Irak fue una manera de conseguirle miles de voluntarios a Al Qaeda, y recurrir a la guerra no era el camino para pacificar el Medio Oriente.

En Estados Unidos, los analistas más críticos acusaron a Francia y Rusia de estar en el Consejo de Seguridad sólo porque 50 años antes habían ganado una guerra. No había que vivir aferrado al pasado, porque el poder mundial había cambiado de dueño ${ }^{26}$.

Las causas principales de la guerra fueron la violación reiterada de los acuerdos de las Naciones Unidas por Hussein durante 12 años, y la amenaza de las ADM. El engorroso sistema de inspecciones, la personalidad del jefe de inspectores de los Estados Unidos, la ambigua actitud del juez suizo Hans Blix, que quedó reflejada en la equidistante posición de su Informe Final, la amenaza de Francia de usar y abusar del derecho a veto, con el apoyo de Rusia y Alemania, que en la práctica abortó la acción del Consejo de Seguridad, entre muchos otros factores, fueron los detonantes inmediatos de la guerra ${ }^{27}$.

\section{Había que cumplir la promesa electoral de frenar el terrorismo mundial.}

Por cierto, la promesa electoral de frenar por todos los medios el terrorismo mundial debía cumplirse. El petróleo era también otra motivación, como enviar al mundo una señal de disciplinamiento y democratización, junto con imponer un plan de viaje a israelitas y palestinos.

Al momento de las decisiones en Washington, Londres y Madrid, las causales anteriores fueron factores sistémicos y concomitantes. En lo esencial, no

${ }^{26}$ Lambert, Richard. "Misunderstanding Each Other", op . cit.

${ }^{27}$ Berdal, Mats. "The UN security Council. Ineffective but Indispensable", Survival, V. 45, No 2, 2003 y Adam Roberts. "Law and the use force after Irak", idem. 
hubo una explicación única para las múltiples motivaciones bélicas.

Como escribió Oriana Fallaci, la guerra "no fue una guerra justa ni humanitaria, sino una guerra política"28.

Para la masa de electores norteamericanos, todavía asustados por el 11.9, y para el círculo íntimo del presidente Bush, los elegantes discursos "principistas" del eje franco-alemán parecían eximir de culpa a los terroristas, a Saddam Husseim, el gran dictador y genocida, mientras que Estados Unidos, Inglaterra y España lo derrocaron en nombre de esos mismos principios.

\section{Hay consenso político en que Irak fue el mayor responsable.}

Los especialistas en derecho internacional que han debatido el tema indican que el grado de responsabilidad ante distintos tipos de violaciones fue diferente, pero hay cierto consenso político de que el peso final de la culpa no exime a Irak haber sido el mayor responsable.

\section{TRES PODERES INDISPENSABLES:}

Estados Unidos, LA Unión EUROPEA

\section{Y LAS NACIONES UNIDAS}

Los prejuicios que existen sobre Estados Unidos en el Viejo Mundo fueron resumidos por Robert Kagan cuando ex- presó que "el poder militar de Estados Unidos ha dado lugar a una tendencia a usar esa fuerza. La debilidad militar de Europa ha producido una comprensible aversión al ejercicio del poder militar. Es más, ha provocado gran interés por habitar un mundo en que la fuerza carezca de importancia, en que predominen el derecho internacional y las instituciones, en que se prohíba la acción unilateral de las naciones poderosas, en que todas las naciones, sin considerar su poder, tienen los mismos derechos y son igualmente protegidas por normas internacionales acordadas"29. A la luz de lo anterior, la imagen que prevalece en Estados Unidos es de una Europa dividida, insegura de sí misma, de su proceso de expansión, de los valores que representan los Estados Unidos y en que Francia no quiere pagar el costo militar de su ambición de poder y de la dificultad económica para lograrlo.

Los postulantes a la UE, la 'nueva Europa', fueron tironeados desde cada extremo del Atlántico para sumarse a su posición. Todos ellos se inclinaron en favor de Estados Unidos e Inglaterra, debido al temor a ser víctimas del unilateralismo del eje franco-alemán. Por su parte, a Estados Unidos no le atemoriza la UE: perciben que está llena de conflictos internos, en especial debido a la heterogeneidad de sus 25 miembros, cada cual con derecho a veto, lo que es sinónimo de parálisis política ${ }^{30}$.

La raíz de un eventual divorcio o con-

\footnotetext{
${ }^{28}$ Falacci, Oriana. "La rabia, el orgullo, la duda", La Tercera, 30 de marzo de 2003.

${ }^{29}$ Kagan, Robert. "Looking for legitimacy", op. cit.; p.71.

${ }^{30}$ Serfaty, Simon. "Europe enlarged, America Detached", op. cit.
} 
gelamiento del atlantismo es un proyecto europeo ambicioso que puede romper el statu quo de poder post Guerra Fría y afectar los intereses de la estrategia de los Estados Unidos. Uno de los que ven esta amenaza es Zbigniew Brzezinski quien expresó: "En el mundo hay Estados que son jugadores geoestratégicos con capacidad y voluntad nacional de ejercer poder e influencia más allá de sus fronteras para alterar -en medida capaz de afectar los intereses estadounidenses- el estado actual de las cuestiones geopolíticas" ${ }^{\prime 31}$.

\section{La globalización de la economía ha dado lugar a numerosas guerras comerciales.}

Además de los obstáculos geopolíticos, la globalización de la economía ha dado lugar a numerosas guerras comerciales. Como reacción a ello, la regionalización de los mercados ha aumentado el comercio intraeuropeo e intra Atlántico y para muchos observadores el fortalecimiento del euro es una manera de complicar las relaciones entre Estados Unidos y Europa, porque ésta se verá inundada de productos norteamericanos. Pese al incremento de los flujos de comercio e inversión dentro de Europa, en especial desde que comenzó a circular el euro, cada uno resguarda su mercado nacional mediante un proteccionismo que no ayuda a la "nueva Europa" ni a América Latina.
En el plano político y comunicacional, muchas de las ambiciones silenciadas durante siglos se expresan ahora sin temor, debido a que la estrategia de cada Estado depende de lo que hagan los demás, a que la proliferación de normas, tribunales y actores altera las percepciones individuales de los miembros de la alianza, los objetivos nacionales y la forma de $\operatorname{lograrlos}^{32}$. Sin embargo todavía Europa no puede defenderse a sí misma, como lo demostró durante la crisis de Bosnia y entre ellos hay demasiadas asimetrías que asemejan a algunos pequeños países europeos con verdaderos protectorados de los Estados Unidos.

Durante la Guerra Fría, la unidad de la alianza transatlántica fue la clave de la seguridad mundial. En la actualidad, el factor esencial de la estabilidad es la unidad europea como tal y no como dependiente y determinada por su relación con Estados Unidos. Según Ole Waever, la seguridad europea depende más de lo que ocurre al interior de Europa que de lo que sucede en la relación entre Estados Unidos y Europa ${ }^{33}$. A su juicio, sólo es posible lograr una Europa en paz independientemente de Estados Unidos. La integración europea es el único camino y la clave de su propia seguridad. Crea seguridad porque produce una identificación de las metas nacionales con los demás y así se construye una Europa más amplia y unida. Coexisten, en armonía y paz, la nación y la estructura supranacional.

${ }^{31}$ Brzezinski, Zbigniew. El gran tablero mundial. La supremacía estadounidense y sus imperativos geoestratégicos, Barcelona, Paidos, 1998; p. 48.

${ }^{32}$ Kupchan, Charles (ed.), Atlantic Security, op. cit.; p. 13.

${ }^{33}$ Waever, Ole. Idem; p. 46. 


\section{La integración europea es la clave de su propia seguridad.}

En este esquema de "aliado natural", podrían aparecer conflictos con Estados Unidos, si se impone el proyecto francés de unificación, elaborado en tiempos en que Alemania estaba dividida e Inglaterra marginada. Para Francia, Europa es la forma de adquirir un estatus global y darle lo que su propio Estado no puede darle actualmente. Con el liderazgo de París, Europa recuperará el sentido de grandeza de los franceses. Por su parte, Alemania, sumergida en la Unión Europea, se redime y aparece como buen ciudadano europeo, purificado y rehabilitado política y moralmente. Al mismo tiempo, reconoce y recibe mayor apoyo de Estados Unidos.

En este contexto, Francia debe contener a la Alemania unificada y a una Gran Bretaña que desea desempeñar un rol clave en el orden post Irak. Alemania y Estados Unidos conocen la debilidad económica y militar de Francia, pese a su poder nuclear. La recuperación económica de Rusia y la reunificación de Alemania dejaron a Francia como perdedor neto, cuya estatura económica y política disminuyó, por lo que no mira con buenos ojos la excesiva ampliación de la Unión. En cambio Alemania y Estados Unidos abogaron más firmemente por la ampliación hacia los países más proclives a Berlín y Washington.

Pese a las divergencias lógicas que se dan entre aliados, Estados Unidos debe apoyar la unificación europea porque de ella dependerá que los valores democráticos se irradien hacia otros mundos. Por su parte, el eje francoalemán no puede llevar la seguridad de Europa sobre sus espaldas, por lo que en las operaciones y ejercicios transatlánticos el ejemplo de las Fuerzas Operativas Conjuntas Combinadas, creadas en 1996.

En definitiva, Europa y Estados Unidos son aliados naturales y como señaló Brzezinsky "Una Europa construida y liderada por Berlín resulta sencillamente imposible, por eso Alemania necesita a Francia, Europa necesita la conexión francoalemana y los Estados Unidos no puede elegir entre Alemania y Francia" ${ }^{\prime 3}$.

De esta manera, la lucha por Europa, no es sólo un asunto de equilibrio de poderes, como lo sugiere Brezezinsky, sino que se relaciona con la construcción de identidades. Es una lucha al interior de cada nación europea. Por ejemplo, en Alemania la nueva generación de líderes, los socialdemócratas y los verdes, se sienten más culpables del holocausto y de la II Guerra, por lo que promueven con vigor la integración, odian la guerra y la política del poder. Helmut Kohl temía con razón una visión geopolítica, porque podía crear una alianza anti Alemania.

En Francia, los enfoques han evolucionado desde Charles de Gaulle, que definió a Europa como la arena en que Francia demostró su poder e independencia. Con Mitterrand, es una Francia estatista, más débil, que se defiende y proyecta su poder y la tercera interpretación,

${ }^{34}$ Brzezinski, Zbigniew. "El gran tablero mundial”, op. cit.; p. 88. 
pierde protagonismo pero es compensada porque Europa sería un poder mundial formidable, simbolizado en la propuesta de Valery Giscard d'Estaing en la Convención Europea. Jacques Chirac, como vocero de la tesis antinorteamericana en la guerra del Golfo, recordó las típicas posturas disidentes de sus predecesores, en especial De Gaulle.

En la guerra de los Balcanes, Europa no pudo defenderse sola y debió recurrir a la acción militar de Estados Unidos y de la OTAN. La denominada guerra de Clinton fue símbolo de esta incapacidad europea de darse seguridad a sí misma. El mismo Brzezinski sugiere que hay que preservar la OTAN por todos los medios, pero no a expensas de la integración europea. En ausencia de desafíos externos, la OTAN necesita de la integración europea, para prevenir las rivalidades internas.

La Unión Europea da garantía de seguridad al continente porque evitaría el retorno a las rivalidades del pasado. Para Estados Unidos esta opción es la que ofrece más esperanzas de una nueva era de relaciones transatlánticas basadas en una Europa segura, unida y en paz. En 2002 las Cumbres de Madrid y Praga demostraron que no será fácil reunir a tantos Estados diferentes bajo el paraguas de un mismo sistema de seguridad ${ }^{35}$.

El académico Stanley Hoffman vio en la globalización a un enemigo de la paz ${ }^{36}$ porque en vez de expandir la paz provoca más conflictos y resentimientos. La denominada "gobernanza global" que existe actualmente es parcial, débil, excluye a los más pobres, reduce la soberanía monetaria y fiscal y obliga a decisiones crueles entre lograr la competitividad o mantener algunos beneficios sociales.

En este ambiente de "fragmentigración", conviene escuchar al historiador que señaló: "Hoy, los Estados Unidos es una superpotencia a la que le falta verdadero poder, un líder mundial que nadie sigue y pocos respetan, una nación que oscila en forma peligrosas en medio de un caos global que no puede controlar" ${ }^{37}$. Las victorias militares pueden esconder graves diferencias sociales, políticas y morales que estallarán en cualquier momento.

\section{Las fuerzas religiosas y espirituales se unieron para criticar el modelo económico neoliberal.}

Tras la guerra de Irak, los movimientos antiglobalización ya iniciaron su cosecha y las plataformas de izquierda lanzaron una campaña antinorteamericana y anticapitalista, como la ocurrida en los mejores años de la Guerra Fría, con la diferencia de que ahora fue global. Diversas fuerzas religiosas y espirituales se

${ }^{35}$ Terrief, Terry and others. "One in, all in? NATO's next enlargement”, International Affairs, Vol. $78, \mathrm{~N}^{\circ} 4$, october 2002.

${ }^{36}$ Hoffmann, Stanley. "Clash of Globalizations", Foreign Affairs, Vol. 81, № 4, July/August. 2002; p. 111.

${ }^{37}$ Wallerstein, Immanuel. "The incredible Shrinking Eagle. The end of Pax Americana", Foreign Policy, July/August, № 131, 2002; p.63. 
unifican para criticar el modelo económico neoliberal como antihumanista, por sus consecuencias culturales y morales.

En Polonia y Checoslovaquia, las fuerzas que hicieron perder el miedo fueron el renacer del sentimiento humanista y religioso, el auge de una religión civil llamada "nacionalismo". Sólo por Dios y la Patria se podían anteponer a los egoísmos y valía la pena luchar por estos ideales, aunque fueran "burgueses". Ahora, en manos de un presidente no católico, Polonia y otros países de la Europa creyente luchan para que se reconozca el legado del cristianismo en el proyecto de Constitución Europea.

En el nuevo equilibrio europeo no hay sólo temor al imperialismo norteamericano, sino también a las minorías que huyen de la persecución étnica o religiosa entre otros lugares de Rusia hacia Europa Central y de allí hacia Roma, París y Bonn. Para frenar esas amenazas los electores europeos, ricos y pobres, de izquierda y de derecha, levantarán nuevas cortinas para cerrar sus fronteras. Una Europa fortaleza en vez de un Hogar europeo sería el fracaso de la Unión.

El Vaticano alertó al mundo sobre las divisiones espirituales, de riqueza y de poder, que separan a los europeos y al mundo entero. Por ello, lanzó una nueva evangelización de Europa para resucitar los valores espirituales que la hicieron grande. Ese Manifiesto Humanista se lanzó desde el mismo lugar en que comenzó la idea de Europa, en las Universidades de Praga y Varsovia. A la luz de esta visión, el Norte y el Sur son indispensables, su destino es como el de hermanos gemelos y el bienestar de uno depende del otro. Este enfoque no excluye ni discrimina a ninguna etnia o cultura, a ningún actor o continente, por débil o fuerte que parez$\mathrm{ca}^{38}$.

\section{El Vaticano lanzó una nueva evangelización de Europa para resucitar los valores espirituales.}

Para los europeos y personas de otros continentes el desafío será conciliar el modernismo con la tradición del humanismo y del cristianismo, reconciliar al Lexus y el Olivo; volver a la raíz, valorar la persona humana por sobre el mercado y el Estado, defender a la pequeña familia y a la gran familia de las diferentes patrias, todos coexistiendo sin exclusiones en un hogar común global. La globalización al servicio del hombre, y no al revés, es la médula del mensaje de los humanistas y los creyentes. No habrá para ellos salvación sin globalización, pero este proceso supone la humanización del denominado "paradigma único" 39 .

${ }^{38}$ Zenit.org.com, Ciudad del Vaticano. "Las obligaciones de Irak deben exigirse en el marco de la ONU. Homilía Cardenal Pío Laghi, Enviado Especial de Juan Pablo II”, miércoles 5, marzo, 2003, Washington DC.

${ }^{39}$ Friedman, L. Thomas. “Tradición versus Innovación”, The Lexus and the Olive Tree, Atlántida, Buenos Aires, 1999. 
VI. UN UP GRADING DEL PARADIGMA DE SEGURIDAD DE LAS NACIONES UNIDAS

¿Cómo enfrentar el desafío de la "gobernanza global"? la Real Academia define la expresión como "la acción y efecto de gobernar o gobernarse" o como "las condiciones financieras y administrativas necesarias para instrumentar y aplicar las decisiones políticas adoptadas y poder ejercer la autoridad" 40 .

Todo intento de crear una plataforma común de países en desarrollo que desean cambiar esta situación de desconcierto debería tener en cuenta ciertas realidades. Éste es el mejor escenario y el momento más oportuno debido a los espacios políticos abiertos por la guerra de Irak al reaparecer nuevos esfuerzos multilateralistas. Se trata de un hito histórico que obliga a la autodisciplina de los actores y que puede abrir nuevas avenidas de cooperación, sin eliminar las tradicionales hipótesis de conflicto. Up grading significa precisamente actualizar las potencialidades en la gestión del conflicto político dentro de parámetros sistémicos dados por el statu quo.

\section{La guerra es un hito histórico que obliga a la autodisciplina de los actores.}

Antes de la guerra y durante ella el multilateralismo fue puesto en jaque, pero el peor momento ya pasó. Es cierto que entre 1990 y 1994 hubo verdadera concordia en el Consejo de Seguridad, época en que se aprobaron 323 resoluciones y hubo tres vetos. Así, se revirtió el comportamiento característico de las potencias durante la Guerra Fría, cuando los europeos, rusos y estadounidenses, en ese orden, fueron los que más abusaron del derecho a veto y bloquearon el sistema de decisiones de las Naciones Unidas ${ }^{41}$.

Aunque es sabido que las grandes potencias usaron a las Naciones Unidas como pantalla para legitimar multilateralmente algunas políticas que aplicaron en distintos lugares del mundo, en octubre del 2001, cuando lanzó la guerra contra los talibanes el Presidente Bush señaló "We are supported by the collective will of the world" lo quepara muchos significa la comunidad internacional. Luego repitió la misma idea "En el Irak post Saddam, las Naciones Unidas definitivamente tendrán un papel... Esperamos que mañana las Naciones Unidas cumplirán su trabajo. Si no, todos nosotros deberíamos retroceder e imaginarnos cómo hacer que funcionen mejor. Con esta promesa, puso un toque de optimismo en la Cumbre de las Azores ${ }^{42}$.

A pocos días de terminada la guerra, en mayo del 2003, el Consejo de Seguri-

${ }^{40}$ North South Center. op. cit.; p.34.

${ }^{41}$ Ortega, Martín. Hacia un gobierno Mundial, Las nuevas funciones del Consejo de Seguridad de Naciones Unidas, Salamanca, Ed. Hespérides, 1995; ver.p.14, "Cuadro de resoluciones y de vetos en el CS por años 1946-1994”. Ver Taylor, Paul. International Organization in the Modern.

${ }^{42}$ World, The regional and the global process, New York, Pinter, 1993. Véase también Fawcett, Eric and Hanna Newcombe. "United Nations reform, Looking ahead after fifty years", Science for Peace, 
dad aprobó por unanimidad la Resolución $\mathrm{N}^{\circ} 1483$ basada en un proyecto presentado por Estados Unidos, Inglaterra y España. Ella dio la señal de que las Naciones Unidas tendrían un papel en la post guerra y que en la reconstrucción de Irak se aplicará el Capítulo VII. Al respecto, Michael Dunne sostiene que la posición de Estados Unidos respecto de las Naciones Unidas no ha variado demasiado en el tiempo y, aunque ahora parezca obvio, no habrá duda de que con o sin su apoyo habría intervenido para derrocar a Saddam. El apoyo de Blair fue importante, pero si Estados Unidos no hubiese atacado a Irak, Inglaterra no habría tomado una opción unilateral como la que adoptót ${ }^{43}$.

\section{Los intereses de Estados Unidos, Europa y las Naciones Unidas convergen en muchas materias.}

Un informe preparado por Estados Unidos para la reforma de las Naciones Unidas señaló claramente que en muchas materias los intereses de éstos, Europa y las Naciones Unidas son convergentes y son ellas las que hay que promover. A manera de ejemplo, cabe citar la lucha contra el terrorismo, las violaciones de los derechos humanos, la idea de crear una comunidad de naciones democráticas, en fin, de convertir la organización en un lugar en que se privilegian la democracia, el mercado y la paz entre las naciones. En esta visión convergen elementos clave de un nuevo paradigma de seguridad internacional que se viene construyendo en el mundo ${ }^{44}$.

Al respecto, la siguiente cita refleja las ideas que influyen en la definición de una nueva concepción de seguridad: "Los conceptos de seguridad internacional fueron construidos a partir del hecho de que el único actor con capacidad de acción política real en el sistema internacional era el Estado. Con la consolidación del proceso de globalización y el surgimiento de nuevos actores internacionales, la concepción estado-céntrica de la seguridad internacional ha experimentado cambios en algunos supuestos básicos: el Estado ha dejado de ser el objeto exclusivo de seguridad; ahora existen otros demandantes de seguridad que no son el Estado. En esta línea se inscribe, por ejemplo, el debate en torno a la seguridad humana, concepto inicialmente acuñado por el Programa de Naciones Unidas para el desarrollo, PNUD, en 1994"45.

Ahora, después de Irak, el momento geopolítico favorece una estrategia de

Toronto, 1995 y "Reforma de las Naciones Unidas,Dossier sobre la reforma de las Naciones Unidas 1997-2002” y “Cronología, 1996-2002”, reform@un.org.

${ }^{43}$ Dunne, Michael. "The US, the UN and Iraq, Multilateralism of a kind", International Affairs, $\mathrm{N}^{\circ}$ 79, N $^{\mathrm{2}}$, March 2003.

${ }^{44}$ Hampson, O. Fen. "Preventive diplomacy at the UN and beyond", en and David Malone, From Reaction to conflict prevention, op. cit., cap. 6. Define las medidas que previenen la erupción de un conflicto violento con medios no coercitivos y coercitivos. Para ello, algunos sugieren dar más poderes a la Secretaría General y otros proponen asociaciones estratégicas con la sociedad civil, ONG, organismos regionales y sector privado.

${ }^{45}$ Ministerio de Defensa, Chile, Libro de la Defensa, Parte II, 2002; p. 9. 
seguridad diferente para la "gobernanza internacional". Apoyar las Naciones Unidas como institución de administración pública universal debería partir por reconocer esta coyuntura, de manera de convertirse en la organización capaz de empoderar al ciudadano, integrar y no excluir en su seno a los intereses de la humanidad en su totalidad y diversidad.

Recordemos que en su Preámbulo la Carta de las Naciones Unidas señala que "se debe respetar", practicar la tolerancia y convivir en paz como buenos vecinos o, como lo prevé el art. 1.3, "respeto a los derechos humanos y a las libertades fundamentales de todos, sin hacer distinción por motivos de raza, sexo, idioma o, religión".

Una "gobernanza global" que tome en cuenta al ciudadano ayudaría a integrar sus funciones, para así contribuir a proporcionar y cuidar de los bienes públicos que necesita toda la humanidad, sería el mejor antídoto para una dominación basada en la hegemonía de uno de sus estamentos o la superioridad basada en alguna característica excepcional que, de ocurrir, sería abiertamente contraria a los valores básicos de la Carta de las Naciones Unidas. En consecuencia, una eventual reforma debería usar una metodología de trabajo compatible con sus valores, que avance desde abajo hacia una genuina, "gobernanza global".

De hecho, al comienzo de los años noventa se criticaron los procedimientos del Consejo de Seguridad por su elitismo y falta de transparencia, lo que dio lugar a que se aplicaran una serie de iniciativas positivas, como las frecuentes declaraciones presidenciales conjuntas, las consultas informales entre los cinco miembros permanentes y la publicidad de los proyectos de resolución en textos azules. Junto con el avance en la transparencia de los aspectos procesales hubo especial preocupación por el mantenimiento de la paz, por lo que se le otorgaron poderes inéditos.

\section{La reforma de la Carta de Naciones Unidas debería utilizar una metodología compatible con sus valores.}

De las resoluciones $\mathrm{N}^{\circ} 690$ a la $\mathrm{N}^{\circ}$ 940, "más de cincuenta mencionan expresamente el capítulo VII, a las que habría que añadir otras que se basan en ellas, que es una proporción realmente alta" ${ }^{46}$.

El Programa de Paz, dado a conocer por el Secretario General el 17 de junio de 1992, ha sido el punto de partida de una serie de atribuciones nuevas del Consejo de Seguridad en materia de mantenimiento de la paz. El Programa define las categorías que permitirán perfeccionarse y terminar con la drástica distinción entre el capítulo VI y VII de la Carta, y distingue entre diplomacia preventiva, establecimiento de la paz, mantenimiento de la paz, resguardo de la paz, consolidación de la paz e imposición de la paz.

Un hito importante en la trayectoria de las nuevas resoluciones del Consejo de Seguridad es la $N^{\circ}$ 687, que impone

\footnotetext{
${ }^{46}$ Ortega, Martín. "Hacia un gobierno Mundial”, op. cit.; pp.18 - 21.
} 
una serie de condiciones a Irak después de su invasión a Kuwait. Esta resolución dio por finalizada la autorización del uso de la fuerza que había otorgado la Resolución $\mathrm{N}^{\mathrm{o}} 678$, la denominada madre de todas las resoluciones ${ }^{47}$.

\section{La guerra de Irak abrió espacios de cooperación en seguridad entre Naciones Unidas y la sociedad mundial.}

Después de la reciente guerra de Irak se abrieron nuevos espacios de cooperación en seguridad entre las Naciones Unidas y la sociedad mundial. El nuevo equilibrio pasa por ampliar las facultades de la Asamblea General mediante la incorporación de algún tipo de mecanismo que haga posible aumentar su representatividad mediante funciones similares a las de un poder legislativo, con la eventual elección de algunos de sus miembros. Por otro lado, la ampliación del actual Consejo de Seguridad con nuevos miembros permanentes y un mecanismo de selección regional que evite onerosas carreras por lograr un asiento en él y pusiera fin a la actual asimetría de poder en su seno. Incluso se han concebido fórmulas esta- dísticas que harían posible una democratización realista de los órganos de las Naciones Unidas ${ }^{48}$.

El derecho a veto puede mantenerse siempre que se extienda en forma calificada a otros miembros rotativos y que a su vez se califique al número de países, más de uno, que permitan bloquear una decisión de uso de la fuerza en otras materias sensibles de quorum calificado.

El Estado continuaría detentando la legitimidad política, por lo que no significa llevar al extremo el principio de no intervención. El Estado ha sido destronado del pedestal que ocupaba en el siglo XIX, e incluso quienes se oponen a la supranacionalidad de la ley aceptan que ya es un hecho y que no reconocerlo puede poner en jaque al propio Estado nación. En el peor de los casos, el Estado podría coexistir con redes de distribución del poder junto con otros Estados, en varios anillos de cooperación multilateral que abarcarían los planos universal de las Naciones Unidas; el ámbito regional, de las organizaciones regionales o continentales; interestatal; federal, y si fuere el caso, local, que es el plano más cercano al ciudadano ${ }^{49}$. En estos círculos de interdependencia cohabitan la soberanía y la no intervención, ajustándose a las nuevas situaciones. Estas funciones nuevas de la

${ }^{47}$ Idem, p. 267.

${ }^{48}$ Hampson, O. Fen. "Preventive diplomacy at the UN and beyond", define las medidas que previenen la erupción de un conflicto violento con medios no coercitivos y coercitivos. Para ello algunos sugieren dar más poderes a la Secretaría General y a los órganos regionales, otros proponen asociaciones estratégicas con la sociedad civil, ONG, organismos regionales y sector privado.

${ }^{49}$ Ortega, idem; ver "Conclusiones", y David Malone. Decision Making in the Security Council. The case of Haiti, Oxford, Clarendon Press, 1998. Se sugiere un rol del Consejo como un ente central legislativo de la seguridad y la paz mundial, una nueva metodología de intervenciones humanitarias manejo de conflictos y de operaciones de paz. 
Asamblea General y del Consejo de Seguridad en materia de seguridad no significan el fin de la soberanía y de la no intervención. Por el contrario, son su complemento.

\section{El Estado ha sido destronado del pedestal que ocupaba en el siglo XIX.}

Después del cincuentenario de las Naciones Unidas, uno de los temas clave del debate ha sido el reconocimiento de la tendencia de la sociedad civil mundial a incorporarse como actor político, que complementa y no destruye la labor tradicional del Estado. De hecho, habrá que incorporar en la Asamblea General en forma permanente a delegados de las asociaciones civiles, de modo que su presencia sea cada vez más reconocida y que la Asamblea se asemeje más a una estructura parlamentaria o de amplia representación social.

Europa y Estados Unidos han vivido períodos de expansionismo y aislacionismo, se han unido y distanciado. Por lo tanto, para algunos autores las crisis recientes no son un fenómeno nuevo, las acciones externas de Estados Unidos son parte de la tradición histórica de intervenir en procesos de nation building. A manera de ejemplo cabe citar su interven- ción en Panamá que duró 33 años, Nicaragua (18), Cuba (3), Vietnam (9), Afganistán (2) y sin que a la larga la mayoría de países intervenidos lograran la democracia al cabo de 10 años. Así, un total de 18 intervenciones, uni y multilaterales, sólo algunos como Japón y Alemania son democracias estables ${ }^{50}$.

Si Estados Unidos rompe su etnocentrismo y su unilateralismo ciego puede asumir un liderazgo cosmopolita, con conductas no hegemónicas, que demostrarán que las formas de ejercer el poder han cambiado para siempre, que ahora el desarrollo y la seguridad son tarea de todos. En vez de generar temor, los líderes de Estados Unidos deben adoptar una actitud que despierte apoyo y demuestre capacidad universal de convocatoria ${ }^{51}$.

Si bien el gobierno mundial necesita un up grading en lo que respecta al funcionamiento de la Asamblea General y del Consejo de Seguridad de las Naciones Unidas, no se trata de convertirlas en otro polo de poder o multipolaridad, sino de abrir espacios para una relación madura de la alianza transatlántica, reconociendo que ambos son indispensables para hacer "gobernable la globalización" e integrando al Consejo a nuevos miembros, con lo cual aumentarán la representatividad y la legitimidad de la organización.

${ }^{50}$ Pei, Mixin y Kasper, Sara. "Lessons from the Past: The American Record in Nation-Building", Carnegie Endowment for International Peace, Washington D.C., May 1th 2003.

${ }^{51}$ Kaldor, Mary. "American power: from compellance to cosmopolitans?", en International Organizations, Vol 79, № 1, 2003. También la Resolución del CSNU 1483, aprobada por 14 de sus 15 miembros, respalda una administración provisional a cargo de irakíes. Es una señal, junto al viaje de Bush a Europa, de que se puede retomar la vía de creación de regímenes internacionales de cooperación en temas de seguridad. 
VII. LECCIONES DE LA GUERRA DE IRAK para AmÉrica Latina. Más allá del ARCHIPIÉLAGO.

Los habitantes del Nuevo Mundo ya están familiarizados con la teoría del excepcionalismo americano y del Destino Manifiesto, que no explicó lo ocurrido con la nueva supremacía de Estados Unidos demostrada en la guerra contra Irak.

\section{América Latina optó por el unilateralismo selectivo.}

Como un archipiélago, América Latina optó por el unilateralismo selectivo, es decir, no actuó en bloque y cada uno actuó según sus propias conveniencias. Algunos gobiernos, en especial los de Centroamérica, apoyaron discretamente a Estados Unidos, otros lamentaron su intervención y los países más importantes coincidieron con la posición del eje francoalemán, dejando a Estados Unidos en situación minoritaria en el Consejo de Seguridad.

Después de la guerra, el hecho de que se haya alineado con los europeos no produjo un distanciamiento de Estados Unidos. Al contrario, podría estar gestándose in vitro una corriente opuesta, de mayor alineamiento con la potencia del norte. Los agudos observadores de Itamaraty ya captaron esta señal y en otros ambientes ligados a la sociedad civil, la opinión pública y la empresa privada, se respira un aire simi$\operatorname{lar}^{52}$.

La actitud de la región fluctuó entre la improvisación, el rechazo, el silencio cómplice, y la tesis de Chile, encapsulada en la frase de la Canciller Soledad Alvear "Chile, lamenta pero no condena". Se trató de una participación independiente y constructiva ${ }^{53}$.

Por cierto, las críticas seudopacifistas sirvieron de caballo de Troya para dar rienda suelta a una retórica antinorteamericana. El dedo acusador de la izquierda apuntó hacia la contención del poderío americano y colocó un tema fresco en su agenda, tranquilizó el descontento popular en lo interno, mientras que con la otra mano dieron señales opuestas y de subordinación a la estrategia de Estados Unidos.

${ }^{52}$ Phillips, Nicole. "Hemispheric integration and sub regionalism in the Americas", International Affairs, Vol. 79, № 2, March 2003.

${ }^{53}$ Alvear, Soledad, Ministra de Relaciones Exteriores, Diario de Sesiones del Senado, 348 legislatura, Sesión 29, 5 de marzo de 2003: "En esta perspectiva y considerando el hecho de que pasados 12 años Iraq mantiene su incumplimiento de las resoluciones del Consejo de Seguridad de las Naciones Unidas... En esta perspectiva, nuestro país debe adoptar una posición con los principios rectores de su política exterior... es una actitud activa, tendiente a generar un esfuerzo político y diplomático como ha sido siempre la política exterior de Chile: agotar -y así lo reiteró el Presidente hace algunos días- todas las medidas políticas y diplomáticas tendientes a evitar el uso de la fuerza... buscar una salida de consenso que, en lo posible, privilegie el multilateralismo"; pp. 3435-3437. Véase también Ministra de Relaciones Exteriores, Cámara de Diputados, Legislatura 348 Extraordinaria, Sesión 52, Publicación Oficial, 5 de marzo, 2003. 


\section{Llegó el momento de profundizar el regionalismo abierto.}

Antes de poner en marcha políticas exteriores convergentes, los Estados desunidos de América Latina deberían primero ponerse de acuerdo en ciertos principios generales e instituciones comunes. Lo curioso es que más allá de la polémica, natural en casos de guerra, en los países de América Latina no podrá haber gobernanza regional, seguridad ni integración a menos que pongan en orden la casa y coordinen sus propias agendas nacionales.

Los amplios espacios que existen en la relación birregional Estados UnidosEuropa deben aprovecharse con políticas de Estado y con criterios de coordinación regional. No es el momento del alineamiento incondicional o de definirse uno en contra de otro, ni de colocar esta relación al servicio de una nueva Guerra Fría, para rechazar uno y afirmar otro. El apoyo a una reforma realista (up grading) de las Naciones Unidas no puede transformarse en válvula de escape de situaciones internas cada vez más críticas; un lenguaje "tercermundista" e ideológico no contribuye a la gobernanza global y agudizaría la irrelevancia estratégica de América Latina en la post guerra de Irak.

Llegó el momento de crear nuevos regímenes de cooperación global, es decir, de profundizar el "regionalismo abierto"; que para los europeos y los latinoamericanos es un método multilateral de contener la hegemonía de Estados Uni- dos, a la vez que un mecanismo de convergencia de esfuerzos para alcanzar un regionalismo multitemático, que incluye la seguridad regional y una serie de subacuerdos que apunten a ajustar las diferencias económicas antes de avanzar hacia una mayor integración, más regional.

Ciudadanos y actores informales, empresarios, trabajadores, el mundo de la cultura y la sociedad civil, deben ser incorporados en estos procesos, para pasar de la integración de los mercados a la de los ciudadanos. Esas voces no se han expresado y su mensaje debe ser articulado e institucionalizado por la diplomacia.

\section{BIBLIOGRAFÍA}

Aldecoa Luzárraga, Francisco, "Innovación política europea”, Política Exterior, Vol. XVII, N ${ }^{\circ}$ 91, enero/febrero, 2003.

Andréani, Gilles. "Why Institutions Matter", Survival, Vol. 43, № 3, Autumn 2001.

Beneyo, José María, “¿Hacia una nueva Unión Europea?", Política Exterior, Vol. XV, № 83, Septiembre 2001.

Armitage, Richard L. "Aliados, amigos, asociados en cada página: visión mundial de paz y seguridad en el siglo 21", Estrategia de seguridad nacional de Estados Unidos, una nueva era, Agenda de la Política Exterior de Estados Unidos, versión electrónica 2002, Vol. 7, № 4.

Brzezinski, Zbigniew. "Vivir con una nueva Europa", Política Exterior, Vol. XIV, No 77, septiembre/ octubre, 2000.

Brotóns, Antonio Ramiro. "La tentación de la agresión, ilegalidad del unilateralismo", Política Exterior, Vol. XVII, N 92, marzo/abril, 2003

BusinessWeek. "The doctrine of digital war", 7 de abril de 2003; pp. 30-50.

Butler, Nick. "Future Perfect Union", Foreign Policy, enero/febrero, 2003. 
Carrasco Morales, Eva. "La UE y el desafío de la ampliación”, Política Exterior, Vol. XV, № 83, septiembre 2001.

Coma, Manuel. "La relación atlántica", Revista Española de Defensa, № 132, Año 12, febrero 1999.

Chesterman, Simon. "Walking Softly in Afghanistan: the Future of UN State-Building", Survival, Vol. 44, No 3, Autumn 2002.

Cheyre, Juan Emilio. "La Seguridad Hemisférica. Una visión centrada en el cono sur", Diplomacia, No 93, Santiago, 2002.

Clarke, Michael y Cornish, Paul. "The European defence project and the Prague summit", International Affairs, Vol 78, $\mathrm{N}^{\circ} 4$, octubre de 2002.

Cumbre de las Américas, "Plan de Acción para fortalecer la democracia, crear prosperidad y desarrollar el potencial humano, en nuestros gobiernos", en: Sistema de Información de la Cumbre de las Américas, Declaración de Principios y Plan de Acción de Québec, 2003.

Daalder, Ivo H. "The End of Atlanticism”, Survival, Vol 45, No 2, Summer 2003.

Dreier, David y Hamilton, Lee H. "Enhancing U.S. Leadership at the United Nations", Report of an Independent Task Force Sponsored by the Council on Foreign Relations and Freedom House, 2002.

Dunne, Michael. "The US, the Un and Iraq", International Affairs, $\mathrm{N}^{\circ}$ 79, 2003.

Evans, Gareth y Sahnoun, Mohamed. "The responsibility to protect", Foreign Affairs, Vol 81, $\mathrm{N}^{\mathrm{o}}$ 6, noviembre/diciembre 2002.

Ferguson, Niall. "Power", Foreign Policy, enero/ febrero 2003.

Gibbs, Nancy. "When the cheering stops", Time, 21 de abril, 2003; pp. 30-39.

Haass, Richard N. y O’Sullivan Meghan L. “Terms of Engagement: Alternatives to Punitive Policies", Survival, Vol 43, N 3, Autumn 2001.

Habermas, Jürgen. "Le statut et les révolutionnaires", Le Monde, Edition Internationale, sábado 10 mayo de 2003.

Hakim, Peter. "Latin America's Lost Illusions", Journal of Democracy, Vol. 14, $\mathrm{N}^{\mathrm{o}} 2$, abril 2003.

Hemmer, Christopher y Katzenstein, Peter. "Why is There No NATO in Asia?", Collective
Identiy, Regionalism, and the Origins of Multilateralism. International Organization, Vol. 56, No 3, Summer 2002.

Hoffmann, Stanley. "Clash of Globalizations", Foreign Affairs, Vol. 81, $\mathrm{N}^{\mathrm{o}} 4$, julio/agosto 2002.

Howorth, Jolyon, "Britain, France and the European Defence Initiative", Survival, Vol. 43, No 3, Autumn 2001.

Kagan, Donald. "The End of wars as the basis for a lasting peace", Naval War College Review, Vol. 53 Issue 4, Autumn 2000.

Kagan, Donald y Kagan, Frederick W. "Nonfiction Britain Between the Wars and America After the Cold War", en While America Sleeps, Vol. 247, Issue 36, 2000.

Kaldor, Mary. "American power: from 'compellance' to cosmopolitanism?", International Organizations, Vol. 79, $\mathrm{N}^{\circ} 1$, enero 2003.

Kay, Sean. "Putting NATO Back Together Again", Current History, Vol. 102, N 662, marzo 2003.

Kupchan, Charles A. "In defence of European Defence: An American Perspective", Survival, Vol 42, No 2 Summer 2000.

Lambert, Richard. "Misunderstanding Each Other", Foreign Affairs, Vol. 8, № 2, marzo/abril 2003.

Lieber, Keir A. "La estrategia de seguridad nacional de Bush", Estrategia de seguridad nacional de Estados Unidos, una nueva era, Agenda de la Política Exterior de Estados Unidos, versión electrónica 2002, Vol. 7, No 4.

Litwak, Robert S. "The New calculus of Pre-emption", Survival, Vol 44, No 4, Winter 2002-03.

Le Monde, "Parodie à l'ÒNU", Edition Internationale, sábado 3 de mayo de 2003.

Moravcsik, Andrew. "Qué pensar de la nueva Constitución de la Unión Europea”, Revista Qué Pasa, 20 de junio 2003.

Moreu Defarges, Philippe. "La UE frente a la crisis iraquî', Política Exterior, Vol. XVII, Nº 92, marzo/abril, 2003.

OEA. "Conferencia Especial de Seguridad, Declaración de Tlatelolco sobre Seguridad Hemisférica", Versión electrónica http:// scm.oas.org, 2003.

OEA. "Vigencia de la OEA", Documento de la Asamblea General, versión electrónica www.oas.org/XXXIIIGA/español, junio, 2003. 
Ortega, Martín. "Europa ante el espejo, la Unión deseable y la posible", Política Exterior, Vol XIV, No 77, septiembre/octubre, 2000.

Ottaway, Marina y Yaphe Judith. "Political Reconstruction in Iraq: A reality Check", Carnegie Endowment for International Peace, Washington D.C., 27 de marzo de 2003.

Palacio, Ana. "La convención europea, un gran avance", Política Exterior, Vol. XVII, N 91, enero/febrero 2003.

Parmentier, Guillaume. "Redressing NATO's Imbalances", Survival, Vol. 43, No 3, Autumn 2001.

Pei, Mixin y Kasper, Sara. "Lessons from the Past: The American Record in Nation-Building", Carnegie Endowment for International Peace, Washington D.C., 1 de mayo de 2003.

Piuzzi, José Miguel. "Relaciones Internacionales y Seguridad Hemisférica: una visión desde la estrategia", Ponencia del Seminario "Las Relaciones Internacionales de Chile en el contexto de la Seguridad hemisférica: una perspectiva estratégica", Academia de Guerra del Ejército de Chile, Santiago, mayo de 2002.

Perspectivas Económicas, "Aplicar la Cuenta del reto del milenio", Vol. 8, $\mathrm{N}^{\circ}$ 2, periódico electrónico del Departamento de Estado de Estados Unidos, 2003.

Powell, Colin L.. Intervención del Secretario de Estado durante la Sesión Plenaria de la Asamblea General de la OEA, Texto Oficial, Embajada de los Estados Unidos en Santiago de Chile, 9 de junio de 2003.

Phillips, Nicole. "Hemispheric integration and sub regionalism in the Americas", International Affairs, Vol. 79, $\mathrm{N}^{\circ} 2$ marzo de 2003.

Pollack, Kenneth M. "Next step Baghdad?", Foreign Affairs, Vol. 81, $\mathrm{N}^{\circ}$ 2, marzo/abril 2002.

Newstateman. "Power to the people, not to Brussels", 2 de junio de 2003.

Rauch, Jonathan. "After Iraq, the Left Has a New Agenda: Contain America First", The Atlantic online, 27 de mayo de 2003.

Rice, Condoleezza. "Un equilibrio de poderes que favorezca la libertad", en Estrategia de seguridad nacional de Estados Unidos, una nueva era, Agenda de la Política Exterior de USA, Vol. 7, No 4, versión electrónica, 2002.
Rodríguez, Álvaro. "Estados Unidos: la ciudad en la cima", Politica Exterior, Vol XVII, No 92 , marzo/abril, 2003.

Rothkopf, David J. "Business Versus Terror", Foreign Policy, mayo/junio 2002.

Rhodes, Edward. “The Imperial Logic of Bush's Liberal Agenda", Survival, Vol. 45, $\mathrm{N}^{\circ} 1$, Spring 2003.

Russell, Donald H. " Transforming the Military", Foreign Affairs, Vol. 81, № 3, 2002.

Sánchez G., Walter. "Europa y EE.UU., espacios de competencia y cooperación", versión preliminar, 2003.

Schneider, William. "Security Redefined", The Atlantic online, 27 de mayo de 2003.

Schrameck, Olivier. "Un antecedente: Francia y Alemania, cooperación abierta", Política Exterior, Vol. XVII, № 92, marzo/abril, 2003.

Serra i Serra, Narcis. "Globalización, fuerzas armadas y democracia en América Latina", FLACSO-Chile, Santiago. Versión electrónica e-boletín, FLACSO-Chile, 9 de septiembre 2002.

Serra i Serra, Narcís. "El progreso de la política de defensa de Europa", Política Exterior, Vol. XV, No 83, septiembre, 2001.

Serfaty, Simon. "Europe Enlarged, America Detached?", Current History, Vol. 102, № 662, marzo 2003.

Slocombe, Walter B. "Force, Pre-emption and Legitimacy", Survival, Vol. 45, No 1, Spring 2003.

Sokolsky, Richard. "Imagining European Missile Defence", Survival, Vol. 43, N ${ }^{\circ} 3$, Autumn 2001.

Solana, Javier. "Tres años como Alto Representante", Política Exterior, Vol. XVII, No 91, enero/febrero 2003.

Stent, Angela y Shevtsova, Lilia. "America, Russia and Europe: a Realignment?", Survival, Vol 44, $\mathrm{N}^{\circ}$ 4, Winter 2002-03.

Strategic Policy Issues, "An Evaluation and Forecast of World Affairs", ISS, U.K. 2002-03.

Stuhldreher, Amalia. "Relación de la Unión Europea con América Latina. Madrid y después", Revista de Estudios Internacionales, $\mathrm{N}^{\circ}$ 139, 2002.

Terrief, Terry y otros. "One in, all in? NATO's next enlargement", International Affairs, Vol. 78, $\mathrm{N}^{\circ} 4$, octubre de 2002. 
The Economist, "Charlemagne, France's man on horseback", 24 de mayo de 2003; pp. 57.

The Economist, "Nemesis", 12 de abril de 2003; pp 9-50.

The Economist, "Taking on the world", 8 de marzo de 2003; pp. 13-14.

Trillo-Figueroa, Federico. "El futuro de la defensa europea tras la cumbre de Praga", Política Exterior, Vol. XVII, N 92, marzo/abril, 2003.
Vecino, Miguel Ángel. "Capitalismo contra democracia, contradicciones de nuestro tiempo", Política Exterior, Vol. XIV, № 77, septiembre/octubre, 2000.

Wallerstein, Immanuel. "The incredible Shrinking Eagle. The end of Pax Americana”, Foreign Policy, julio/agosto, 2002. 